\title{
Superiority of collaborative learning with complex tasks: A research note on an alternative affective explanation
}

Citation for published version (APA):

Kirschner, F., Paas, F., \& Kirschner, P. A. (2011). Superiority of collaborative learning with complex tasks: A research note on an alternative affective explanation. Computers in Human Behavior, 27(1), 53-57.

https://doi.org/10.1016/j.chb.2010.05.012

DOI:

10.1016/j.chb.2010.05.012

Document status and date:

Published: 01/01/2011

Document Version:

Peer reviewed version

Document license:

CC BY-SA

Please check the document version of this publication:

- A submitted manuscript is the version of the article upon submission and before peer-review. There can be important differences between the submitted version and the official published version of record. People interested in the research are advised to contact the author for the final version of the publication, or visit the DOI to the publisher's website.

- The final author version and the galley proof are versions of the publication after peer review.

- The final published version features the final layout of the paper including the volume, issue and page numbers.

Link to publication

\section{General rights}

Copyright and moral rights for the publications made accessible in the public portal are retained by the authors and/or other copyright owners and it is a condition of accessing publications that users recognise and abide by the legal requirements associated with these rights.

- Users may download and print one copy of any publication from the public portal for the purpose of private study or research.

- You may not further distribute the material or use it for any profit-making activity or commercial gain

- You may freely distribute the URL identifying the publication in the public portal.

If the publication is distributed under the terms of Article $25 f a$ of the Dutch Copyright Act, indicated by the "Taverne" license above, please follow below link for the End User Agreement:

https://www.ou.nl/taverne-agreement

Take down policy

If you believe that this document breaches copyright please contact us at:

pure-support@ou.nl

providing details and we will investigate your claim.

Downloaded from https://research.ou.nl/ on date: 26 Apr. 2023 
Running head: SUPERIORITY OF COLLABORATIVE LEARNING

Superiority of Collaborative Learning with Complex Tasks: A Research Note on an Alternative Affective Explanation Femke Kirschner $^{1,2^{*}}$, Fred Paas ${ }^{1,2}$, and Paul A. Kirschner ${ }^{1}$

${ }^{1}$ Centre for Learning Sciences and Technologies, Open University of the Netherlands ${ }^{2}$ Institute of Psychology, Erasmus University Rotterdam, the Netherlands

${ }^{*}$ Correspondence concerning this article can be sent to Femke Kirschner, Institute of Psychology, Erasmus University Rotterdam, The Netherlands, P.O. Box 1738, 3000 DR Rotterdam, The Netherlands, e-mail address kirschner@fsw.eur.nl 


\begin{abstract}
Kirschner, Paas, and Kirschner (2009c) used the theoretical framework of cognitive load to explain why the learning of a group of collaborating individuals was more efficient than that of individuals learning alone with high-complexity tasks but not with low-complexity tasks. The authors argued that collaboration circumvented the limitations of an individual's working memory by creating an expanded cognitive capacity and by allowing for the distribution of cognitive load among group members. Inspired by research on efficacy, this study explored an alternative affective explanation of the results. By measuring the amount of mental effort learners expected to invest in working on a learning task before actually carrying out the task, this study showed that learners who had to collaboratively solve a high-complexity problem expected to invest less mental effort than learners who had to solve the problem alone. When confronted with low-complexity tasks, the expected amount of mental effort did not differ.
\end{abstract}


Superiority of Collaborative Learning with Complex Tasks: A Research Note on an Alternative Affective Explanation

Cognitive load theory (CLT: Paas, Renkl, \& Sweller, 2003; Sweller, 1988) states that instructional procedures that ignore the structures that constitute human cognitive architecture are not likely to be effective. Human cognitive architecture consists of an effectively unlimited long term memory, which interacts with a working memory that is very limited in both capacity (Baddeley, 1986; Miller, 1956) and duration (Peterson \& Peterson, 1959). For new, yet to be learned information, the processing capacity is limited to only $4 \pm 1$ elements, and if not rehearsed, the information is lost within 30 seconds (Cowan, 2001). With complex or cognitively demanding tasks the limited processing capacity is considered to be a bottleneck for successful learning. Kirschner, Paas, and Kirschner (2009a, 2009b) have argued that one way to overcome this limitation at the individual level is by using groups of collaborating learners.

When collaborating learners are seen as information processing systems (Hinsz, Tindale, \& Vollrath, 1997; Kirschner et al., 2009b; Tindale \& Kameda, 2000), it can be argued that the processing of information necessary for carrying out a learning task can be distributed across multiple collaborating working memories, creating a larger reservoir of cognitive capacity. Based on CLT, this expansion of cognitive capacity has been used as a cognitive explanation for the findings that for tasks imposing high cognitive load upon the individual learner, the process of learning in collaboration was more effective (i.e., higher learning performance) and more efficient (i.e., more favorable relation between attained performance and invested mental effort) than the process of learning individually. In contrast, with tasks imposing a low cognitive load, the individual learner had sufficient cognitive capacity to successfully carry out the task individually and the advantage of expanding cognitive capacity disappeared (Kirschner, Paas, \& Kirschner, 2009a, 2009c). This finding 
was argued to be related to the functioning of working memory, which has difficulties with the processing of new information when element interactivity is high (i.e., high complexity tasks) but not when element interactivity is low (i.e., low complexity tasks). Similar results, indicating that cognitive load effects are only found with high complexity tasks, have been found in numerous studies (Sweller, 1994; Sweller, 2004; Sweller \& Chandler, 1994). Examples of such cognitive load effects are the split-attention, modality, and redundancy effects (see Chandler \& Sweller, 1996; Marcus, Cooper, \& Sweller, 1996; Sweller \& Chandler, 1994; Tindall-Ford, Chandler, \& Sweller, 1997). Consistent with those results, the expertise reversal effect (Kalyuga, Ayres, Chandler, \& Sweller, 2003), indicates that the instructional principles based on CLT positively affect novices’ learning, but has no or negative effects on the learning of more advanced learners. Although the cognitive explanation provides an interesting perspective on the effectiveness and efficiency of collaborative versus individual learning, the prospect of knowing that cognitive capacity can or cannot be shared within a collaborating group, and the resulting confidence in being able to successfully complete a learning task, could be an alternative explanation of the results. This article explores this affective explanation.

According to this affective explanation, which is inspired by research on self-efficacy and group-efficacy (Bandura, 1986, 1997), it can be argued that learners who will work together in a group on cognitively demanding (i.e., high-complexity tasks) tasks will have more confidence in being able to successfully complete the learning task than learners who will work individually. Whereas group members can rely on an expanded cognitive capacity and on the possibility to distribute the cognitive load among group members, individual learners can only rely on their own limited cognitive capacity. In cases where the learning tasks are not cognitively demanding (i.e., low-complexity tasks), there should be no difference in confidence in successful task completion between learners who will work 
together in a group and learners who will work individually. When learning from lowcomplexity tasks the limited cognitive capacity of an individual learner would be sufficient to successfully complete the learning task and the expanded cognitive capacity and distribution advantage would not necessarily be advantageous.

Self-efficacy refers to a person's belief in his or her capability to perform a task (Bandura, 1986, 1997). Group-efficacy (also referred to as collective efficacy) is an extension of Bandura’s (1997) concept of self-efficacy to groups, and refers to a person's belief in the capacity of the group to perform a specific task (Bandura, 1986, 1997). Bandura (2000) states that

[t]he growing interdependence of human functioning is placing a premium on the exercise of collective agency through shared beliefs in the power to produce effects by collective action...Perceived collective efficacy fosters groups' motivational commitment to their missions, resilience to adversity, and performance accomplishments. (p. 75)

These collective efficacy beliefs refer to the aggregate or sum of individual group members’ perceptions of their own and group capability. They are the perceptions of members of a team that the team as a whole can organize and execute the courses of action necessary for the successful completion of a task.

Although not as straightforward as self-efficacy, group-efficacy has been shown to be a determinant of the effectiveness of group performance (e.g., Bandura, 1993; Goddard, 2002; Pescosolido, 2001; Silver \& Bufiano, 1996). Pescosolido (2001), for example, found that group efficacy has beneficial effects on group dynamics and on the overall group effectiveness. Another finding of group learning research is that working in a group instead of individually can have positive effects on the confidence that learners have in successful task 
completion (Lent, Schmidt, \& Schmidt, 2006; Puncochar \& Fox, 2004); learners in a group were more confident than learners learning individually.

If working in a group positively effects confidence in successful task completion, then the prospect of being able to work together at the group level (i.e., high confidence), as compared to the prospect of having to rely on ones own effort at the individual level (i.e., low confidence), could explain the finding of Kirschner et al. (2009a, 2009c) as to why a individuals who worked in a group on high-complexity tasks outperformed and learned more efficiently (i.e., indicated by a more favorable relation between performance and mental effort) than individuals who worked alone. With low-complexity tasks, which could be successfully completed by each individual, groups and individuals were probably equally confident and therefore performed equally well with equal efficiency.

Learners' beliefs in their capacity to carry out learning tasks within a group or on their own were expected to become visible in the amount of mental effort they think they would have to invest to successfully carry out the task; the higher the confidence, the lower the mental effort learners expect to invest in successful task completion. It was hypothesized that learners who have to work on high-complexity (i.e., high cognitive load) tasks in a group would have more confidence in successful task completion and therefore expect to invest less mental effort than learners who have to work individually. Higher confidence of group members was expected because they can rely on an expanded cognitive capacity and on the possibility to distribute the cognitive load among each other. With low-complexity tasks (i.e., low cognitive load), the limited cognitive capacity of an individual would be sufficient to successfully complete a task alone, and consequently both group of learners who will work in a group and those who will work individually were hypothesized to have high confidence in successful task completion and therefore expect to invest an equal amount of mental effort. 
To test this alternative affective explanation, this study used a pre-measurement of mental effort to determine the amount of effort learners expected to invest in the successful completion of learning tasks, either as a member of a group or individually.

\section{Method $^{1}$}

\section{Participants}

Participants were 53 second year Dutch high school students (17 boys, 36 girls) with an average age of 13.3 years $(S D=.47)$. They participated in the experiment as part of their regular mathematics curriculum and did not receive any academic or financial compensation. Prior knowledge on mathematics-related subjects was assumed to be the same for all participants, since all students had followed exactly the same math courses during the previous two years and in that period they did not have any prior experience in or exposure to learning tasks like the ones used in the experiment (i.e., calculation of areas of plane shapes, which were a combination of rectangles with triangles and rectangles with circles).

\section{Materials}

All materials were in the domain of mathematics and dealt with calculating areas of plane shapes (i.e., the area of rectangles, triangles and circles). An introduction on how to calculate areas of plane shapes, high and low-complexity learning tasks, and transfer test tasks were designed. All materials were paper-based.

Introduction. The introduction provided information on he calculation of the area of an already known geometrical shape: the rectangle, and two new geometrical shapes: the circle and the triangle. For every geometrical shape, the method for calculating the area, together with a worked-out example showing step by step how to do this when solving an area of plane shape calculation problem, was the core of the introduction. The three instructions gave

\footnotetext{
$1 \quad$ For more detailed information about the method of this study see Kirschner, Paas, and Kirschner (2009c)
} 
insight into the relevant formulas and shapes and were treated separately in the order of rectangle, triangle, and circle.

Learning tasks. Learning tasks were of low and high complexity. For each of these two levels of task complexity, two tasks were developed. One task was based on a rectanglecircle combination and the other on a rectangle-triangle combination (for an example of the latter combination see Figure 1). Task complexity or intrinsic cognitive load was determined by using Sweller and Chandler’s (1994) method based on the number of interacting information elements in a task and the insight necessary for solving the problem. Lowcomplexity tasks contained three information elements that needed to be combined to calculate the area. High-complexity tasks not only contained six information elements that needed to be combined to calculate the area, but also required more insight into the geometrical shape than in the low-complexity task. All tasks consisted of a geometrical shape, a certain number of information elements concerning the shape (i.e., length, proportion, width, shape), and a calculation question on either the whole area or a part of the area (see Figure 1a for an example of a low-complexity task, and Figure 1b for an example of a highcomplexity task). For participants in the group condition, the tasks were structured in such a way that task interdependence was high (Saavedra, Early, \& Van Dyne, 1993), that is, group members had to rely on each other and interact with each other to obtain resources and to effectively carry out the task. More specifically, each group member was assigned a booklet containing only one third of the total number of information elements needed to solve the problem (i.e., one information element per group member for the low complexity tasks and two information elements per group member for the high complexity tasks). None of the information elements were redundant and the number of information elements was equal for all group members. For the learning task depicted in figure 1a this would mean that only one group member received the information that side $\mathrm{KL}$ was $4,5 \mathrm{~cm}$, only one group 
member received the information that side $\mathrm{KP}$ was $3 \mathrm{~cm}$, and only one group member received the information that side NQ was $6 \mathrm{~cm}$. To answer the question "Calculate the area of this shape in $\mathrm{cm}^{2}$ ” group members had to exchange their unique information with each other. Participants in the individual condition received a booklet containing all the information elements needed to solve the problem (i.e., three information elements for the low complexity tasks and six information elements for the high complexity tasks). Participants were not allowed to use pencil and paper.

Insert Figure 1 about here

Cognitive load measurement. Participants, learning both in groups and individually, were asked prior to performing each learning task how much mental effort they thought they would have to invest to successfully perform the task. To this end, they were asked to briefly look at the task and then rate how much mental effort they expected to invest in successfully completing the task (How much effort do you think you will have to invest to successfully solve this problem?). The rating scale used was based on the 9-point cognitive load rating scale developed by Paas (1992) which ranged from very, very low effort (1) to very, very high effort (9).

\section{Design and Procedure}

Two days prior to receiving the learning tasks, all participants received a written instruction on how to calculate the areas of rectangles, circles, and triangles. They had $7 \mathrm{~min}$ to study each geometrical shape individually, after which the teacher had 7 min to discuss both the theory and a worked example in class and give clarification answers to questions asked by the participants. The total instruction took 50 min after which the participants had to hand in the written instructions to the teacher. 
In the learning phase, because of the within subject design of this study, every participant at one point, worked on the learning tasks individually as well as in a 3-person group (i.e., triad). The order of individual and group work, as well as task subject with which a participant started (i.e., rectangle-circle combination or rectangle-triangle combination) was counterbalanced. At the beginning of the learning phase, participants were randomly assigned to the individual or group condition in such a way that half began working individually on two tasks at two different complexity levels and then worked in triads on two other tasks at these same two complexity levels while the other half began working in triads on these problems and then worked individually. With regard to counterbalancing the task subjects, regardless of whether the learners first learned collaboratively or alone, if they first worked on the calculation of the area of a rectangle-triangle combination, then the second time they received the rectangle-circle combination. If participants first worked on the calculation of the area of a rectangle-circle combination, the second time they received the rectangle-triangle combination. After the participants knew whether they had to work in a group or individually, they were presented with a low-complexity task and asked to rate how much mental effort they expected to invest in performing that task successfully (i.e., pre-measurement). Then they worked on the task for $7 \mathrm{~min}$. The sequence was repeated with a high-complexity task. Working in groups differed from working individually in that group members had to communicate with each other during the problem solving process while individuals had to solve the problem alone.

\section{Results}

A significance level of .05 was used for all analyses. Registration problems resulted in incomplete data from 3 participants who were excluded from the analysis. Cohen's $f^{2}$ statistic was used as an effect size index when conducting repeated measures ANOVAs, where $f^{2}$ 
values of .02, .15, and .35 corresponded to small, medium, and large effects respectively (Cohen, 1988).

Results on the pre-measurement of expected mental effort as a function of task complexity were analyzed using a 2 (learning condition: individual vs. group) $\times 2$ (task complexity: low vs. high) ANOVA with repeated measures on both factors. The pre-mental effort scores reported by the participants were used as dependent variable (for means and standard deviations see Figure 2). With regard to the pre-mental effort scores, the ANOVA revealed a significant main effect for task complexity, $F(1,49)=61.88, M S E=0.95, p<.001$, $f^{2}=0.46$, indicating that participants expected to invest higher amounts of mental effort in successfully working on high-complexity tasks than before working on low-complexity tasks. The main effect of learning condition was significant, $F(1,49)=5.10, M S E=1.73, p<.05$, $f^{2}=0.05$, indicating that group members expected to invest lower amounts of mental effort than individuals. In addition, the interaction between task complexity and learning condition was significant, $F(1,98)=8.37, M S E=0.86, p<.05, f^{2}=0.06$. To determine the nature of this interaction (see Figure 2), dependent samples t-tests (one-tailed) were conducted. Using a Bonferroni correction this analysis indicated that those who worked in a group and those who worked individually expected that the same amount of mental effort would be needed to carry out the low-complexity task, $t(49)=0.19, n s$; but when predicting the amount of mental effort needed to carry out the high-complexity tasks, those learning in a group expected that they would need to expend a significantly lower amount of mental effort than those learning individually, $t(50)=3.49, p<.02$ (one-tailed).

\section{Discussion}

Kirschner et al. (2009c) demonstrated that collaborative learning is more effective (i.e., higher learning performance) and more efficient (i.e., a more favorable relation between 
learning performance and invested mental effort) than individual learning if the load imposed by the learning task exceeds the limited processing capacity of an individual. Based on CLT, they argued that with complex learning tasks (i.e., tasks imposing a high cognitive load), collaboration increases the processing efficiency, as the load can be distributed across a larger reservoir of cognitive capacity. In this study, we showed that in addition to this cognitive explanation, the results could also be explained by an affective explanation based on perceptions of efficacy; learners' beliefs in their own and/or the group’s (cognitively) capacity to perform a specific task. By measuring the amount of mental effort learners expected to invest in successfully working on a learning task before actually carrying out the task, this study showed that learners who had to solve a complex problem with other learners expected to invest less mental effort than learners who had to solve the problem alone. When confronted with low-complexity tasks, the expected amount of mental effort did not differ between learners who had to solve the problems within a group and those who had to solve it individually. Moreover, independent of the prospect of being able to work on a problem in a group or individually, learners expected to invest more mental effort in successfully completing high-complexity tasks than in successfully completing low-complexity tasks. Task complexity - or the challenges a learning task imposes on the limited cognitive capacity of the learner - seems to be an important factor for determining the expected amount of mental effort that needs to be invested for successful task performance. From this efficacy point of view, the prospect of collaboration leads to learners feeling more confident about successful task completion with high-complexity tasks that are difficult to solve by a single learner. In contrast, with low-complexity tasks which can be completed successfully by a single learner, the prospect of collaboration does not differentially affect the confidence of group and individual learners in their ability to successfully complete a task. 
With regard to pre mental effort measurement it should, however, be noted that the amount of mental effort learners think they would have to invest to successfully carry out the task, is no traditional measure of learners' beliefs in their capabilities to carry out learning tasks successfully within a group (i.e., group efficacy) or on their own (i.e., self efficacy). When measuring self-efficacy, researchers typically ask learners for a yes or no response to the question whether they can perform a specific task at specific levels (i.e., self-efficacy magnitude), ask learners to rate their degree of confidence in that endorsement on a scale from total uncertainty to total certainty at each specific performance level (i.e., self-efficacy strength), or both (Bandura, 1977). Researchers assessing self-efficacy combine these magnitude and/or strength scores in numerous ways (Lee \& Bobko, 1992; 1994). In this study we used a pre-measurement of mental effort as an indicator of a learner's confidence in completing a task successfully instead of one of the more traditional measurements of selfefficacy. It should be clear that our interpretation of the results regarding the pre measurement of mental effort in terms of self-efficacy is speculative and needs to be taken with caution. Future studies should get more insight into the value of the pre-mental effort measure as an indicator of efficacy.

Mental effort measurements are normally collected during or after the learning phase and when related to the performance scores, they can provide an indication of the type of load imposed on the learner, the quality of the learning outcomes, and the quality of different instructional conditions (Paas \& Van Merrienboer, 1993; Van Gog \& Paas, 2008). In future studies it would be interesting to investigate how the measurement of mental effort before performing the task relates to the conventional measures taken during or after performing the task.

Another topic for future research is trying to identify the level of task complexity and learner expertise at which group members rather than individuals feel more confident to solve 
a task. Such levels will depend on an interaction between task complexity, which is defined as the number of interacting elements in a task, and learner expertise, which is defined in terms of the quality and quantity of the schemas in the learner's long term memory (Paas et al., 2003). Therefore, it can be expected that the task-complexity threshold at which group members are more confident than individual learners will vary as a function of learner expertise. Perceptions of efficacy for various individual and collective pursuits arise from cognitive and metacognitive processing of the sources of efficacy belief-shaping information (Bandura, 1997, 2000). One important source of information is the prospect of being able to jointly bundle efforts to perform the task. This bundling of effort links both the affective explanation provided in this study and the cognitive explanations formulated in previous studies. With high-complexity tasks, groups may feel more confident because they might use the processing capacity, expertise and knowledge of others while working on the task, and because the high cognitive load can be distributed among group members. The results of this study suggest that the higher efficiency of collaborative learning with high-complexity cognitive tasks can be explained by both cognitive and affective factors. The relative contribution of each explanation might depend on task characteristics, such as task complexity, and learner characteristics (see previously discussed level of expertise), and characteristics of the group such as group composition. Future research could explore how those characteristics contribute to the cognitive and the affective explanations and how they affect learning efficiency of groups and individuals.

In conclusion, besides the cognitive explanations of the relationship between task complexity and the effectiveness of individual and collaborative learning (see Paas, Tuovinen, Van Merrienboer, \& Darabi, 2005) it seems worthwhile to explore affective explanations of this relationship. 


\section{References}

Bandura, A. (1977). Self-efficacy: Toward a unifying theory f behavioral change. Psychological Review, 4, 191-215.

Bandura. A. (1986). Social foundations of thought and action: A social cognitive theory. Englewood Cliffs, NJ: Prentice-Hall.

Bandura, A. (1993). Perceived self-efficacy in cognitive development and functioning. Educational Psychologist, 28, 117-148.

Bandura. A. (1997). Self-efficacy: The exercise of control. New York: W. H. Freeman.

Bandura, A. (2000). Exercise of human agency through collective efficacy. Current Directions in Psychological Science, 9, 75-78.

Baddeley, A. D. (1986). Working memory. Oxford: Clarendon Press.

Chandler, P., \& Sweller, J. (1996). Cognitive load while learning to use a computer program. Applied Cognitive Psychology, 10, 151-170.

Cohen, J. (1988). Statistical power analysis for the behavioral sciences $\left(2^{\text {nd }}\right.$ ed.). Hillsdale, NJ: Erlbaum.

Cowan, N. (2001). The magical number 4 in short-term memory: A reconsideration of metal storage capacity. Behavioral and Brain Sciences, 24, 87-114.

Goddard, R. D. (2002). A theoretical and empirical analysis of the measurement of collective efficacy: The development of a short form. Educational and Psychological Measurement, 62, 97-110.

Goddard, R. D., Hoy, W. K., \& Hoy, A. W. (2004). Collective efficacy beliefs: Theoretical developments, empirical evidence, and future directions. Educational Researcher, 33(3), 3-13.

Hinsz, V. B., Tindale, R. S., \& Vollrath, D. A. (1997). The emerging conceptualization of groups as information processors. Psychological Bulletin, 121, 43-64. 
Kirschner, F., Paas, F., \& Kirschner, P. A. (2009a). Individual and group-based learning from complex cognitive tasks: Effects on retention and transfer efficiency. Computers in Human Behavior, 25, 306-314.

Kirschner, F., Paas, F., \& Kirschner, P. A. (2009b). A cognitive load approach to collaborative learning: United brains for complex tasks. Educational Psychology Review, 21, 31-42.

Kirschner, F., Paas. F., \& Kirschner, P. A. (2009c). Efficiency of individual versus group learning as a function of task complexity. Manuscript submitted for publication.

Lee, C., \& Bobko, P. (1992). Exploring the meaning and usefulness of measures of subjective goal difficulty. Journal of Applied Social Psychology, 22, 1417-1428.

Lee, C., \& Bobko, P. (1994). Self-efficacy beliefs: Comparison of five measures. Journal of Applied Psychology, 79, 364-369.

Lent, R. W., Schmidt, J., \& Schmidt, L. (2006). Collective efficacy beliefs in student work teams: Relation to self-efficacy, cohesion, and performance. Journal of Vocational Behaviour, 68, 73-84.

Marcus, N., Cooper, M., \& Sweller, J. (1996). Understand instructions. Journal of Educational Psychology. 88, 49-63.

Miller, G. (1956). The magical number seven, plus or minus two: Some limits on our capacity for processing information. Psychological Review, 63, 81-97.

Paas, F. (1992). Training strategies for attaining transfer of problem-solving skill in statistics: A cognitive-load approach. Journal of Educational Psychology, 84, 429-434.

Paas, F., Renkl, A., \& Sweller, J. (2003). Cognitive load theory and instructional design: Recent developments. Educational Psychologist, 38, 1-4.

Paas, F., Tuovinen, J., Van Merriënboer, J. J. G., \& Darabi, A. (2005). A motivational perspective on the relation between mental effort and performance: Optimizing learner 
involvement in instruction. Educational Technology, Research \& Development, 53, 2533.

Pescosolido, A. (2001). Informal leaders and the development of group efficacy. Small Group Research, 32, 74-93.

Peterson, L. R., \& Peterson, M. J. (1959). Short-term retention of individual verbal items. Journal of Experimental Psychology, 58, 193-198.

Puncochar, J. M., \& Fox, P. W. (2004). Confidence in individual and group decision making: When "two heads" are worse than one. Journal of Educational Psychology, 96, 582591.

Saavedra, R. P., Early, P. C., \& Van Dyne, L. (1993). Complex interdependence in taskperforming groups, Journal of Applied Psychology, 78, 61-72.

Silver, S., \& Bufiano, M. (1996). The impact of group efficacy and group goals on group task performance. Small Group Research, 27, 55-72.

Sweller, J. (1988). Cognitive load during problem-solving: Effects on learning. Cognitive Science, 12, 257-285.

Sweller, J. (1994). Cognitive load theory, learning difficulty, and instructional design. Learning and Instruction, 4, 293-312.

Sweller, J. (2004). Instructional design consequences of an analogy between evolution by natural selection and human cognitive architecture. Instructional Science, 32, 9-31.

Sweller, J., \& Chandler, P. (1994). Why some material is difficult to learn. Cognition \& Instruction, 12, 185-233.

Tindale, R. S., \& Kameda, T. (2000). Social sharedness as a unifying theme for information processing in groups. Group Processes and Intergroup Relations, 3, 123-140.

Tindall-Ford, S., Chandler, P., \& Sweller, J. (1997). When two sensory modes are better than one. Journal of Experimental Psychology: Applied, 3, 257-287. 
Figure 1. A low (a) and high (b) complexity learning task on area calculation of the rectangletriangle combination.

Figure 2. Pre mental effort: Interaction between learning condition and task complexity in the learning phase. 


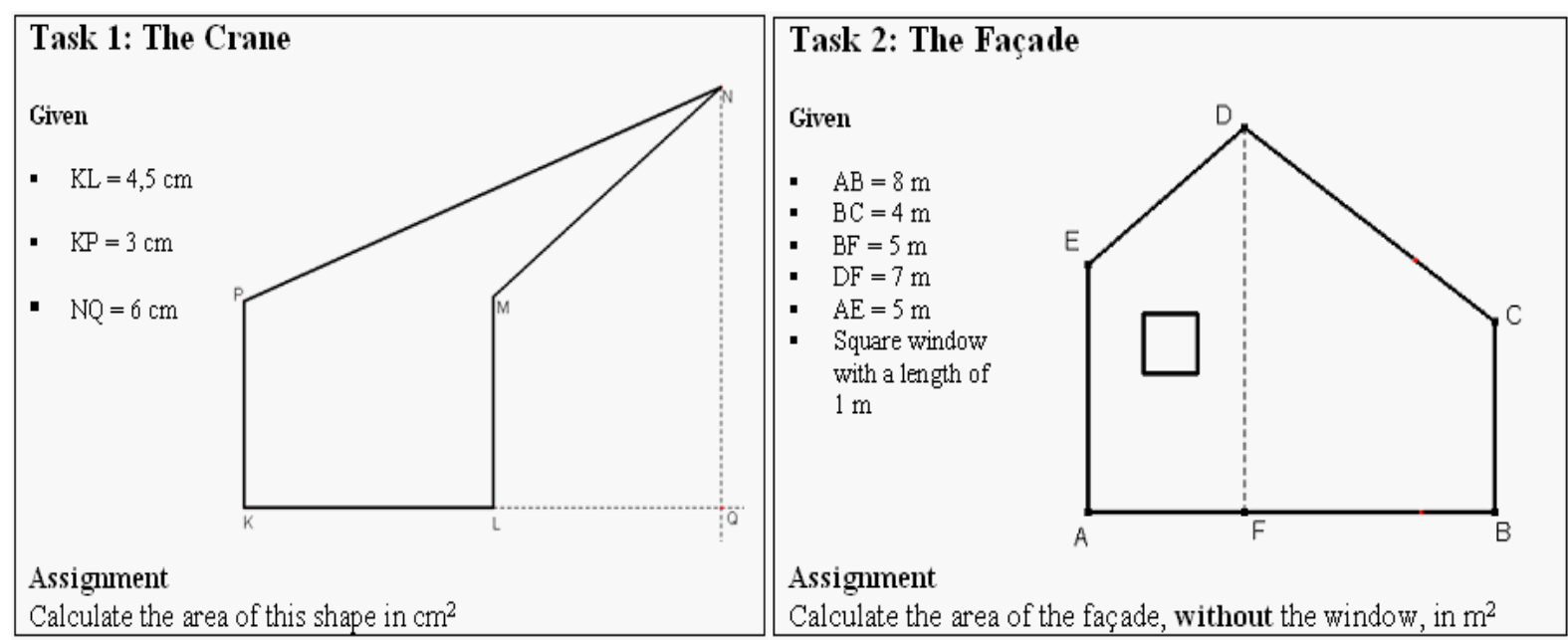

a.

b. 


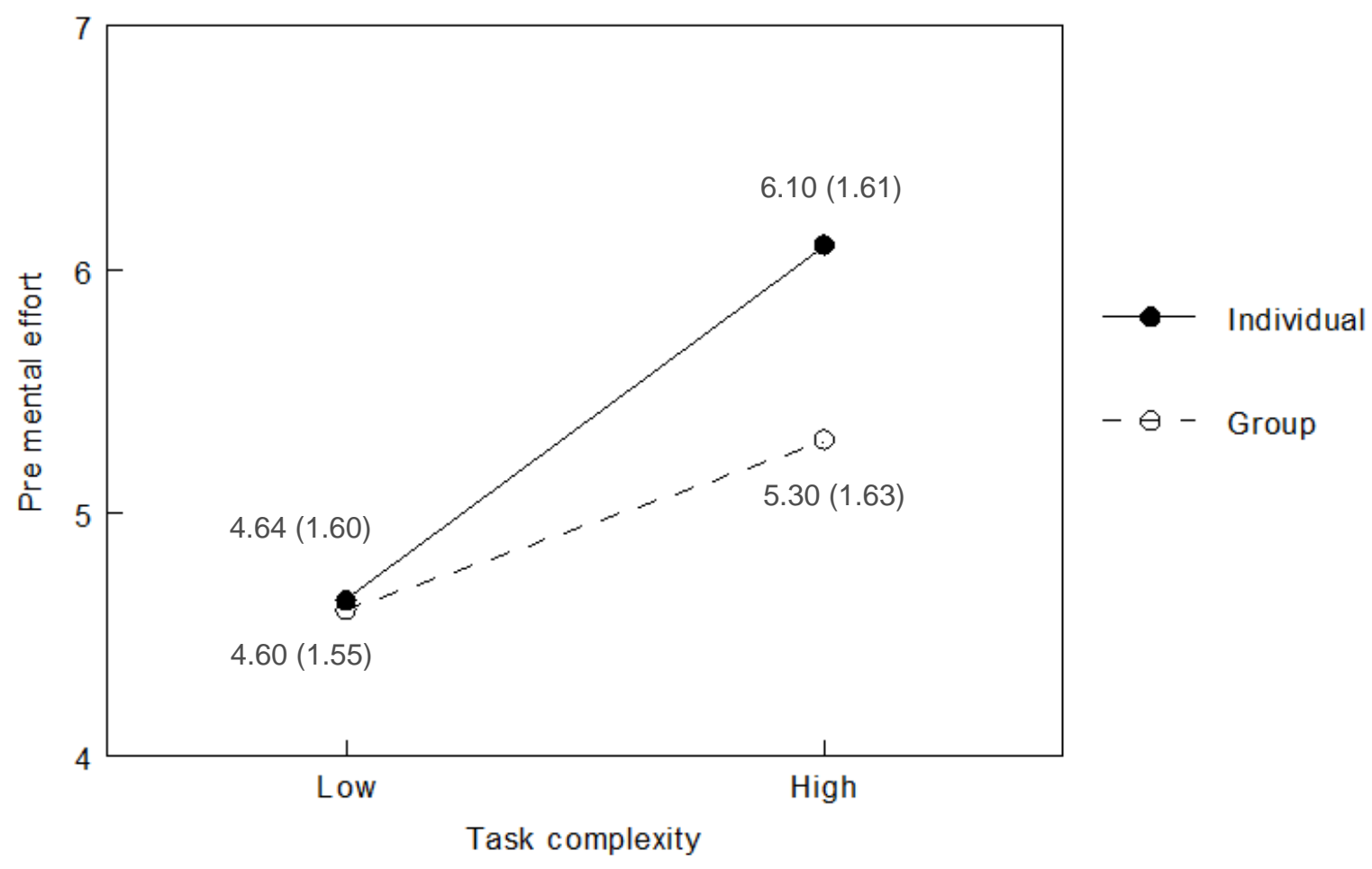

